\title{
Preliminary Notes
}

PN $\mathrm{IOO94}$

\section{Enzymatic transfer of the $\gamma$-glutamyl group between naturally occurring aniline and phenylhydrazine derivatives in the genus Agaricus}

This report describes an unusual substrate specificity associated with the $\gamma$-glutamyltransferase present in sporophores of Aguricus bisporus, the mushroom of commerce in the United States. A study of the properties of such an enzyme from this organism was prompted by recent reports of the isolation and characterization of two unique $\gamma$-glutamyl derivatives, $N$ - $(\gamma$-L- $(+)$-glutamyl $)$ - $p$-hydroxyaniline ${ }^{1}$ and $\beta$ - $N$ - $(\gamma$-L- $(+)$ glutamyl)- $p$-hydroxymethylphenylhydrazine (agaritine) ${ }^{\mathbf{2}, 3}$ from fruiting bodies of species of Agaricus ${ }^{*}$. Recognition of an enzyme in soluble extracts of $A$. bisporus that catalyzed the hydrolysis of the hydrazide linkage of agaritine ${ }^{2}$ led us to investigate the possibility that such a reaction might reflect the functioning of an enzymatic process for the transfer of $\gamma$-glutamyl residues to other acceptors in addition to water.

Protein preparations from $A$. bisporus, purified for hydrolase activity about 26-fold by DEAE-cellulose column chromatography and precipitation with $\left(\mathrm{NH}_{4}\right)_{2} \mathrm{SO}_{4}$, catalyzed the synthesis of $\gamma$-glutamylhydroxamic acid when incubated with L-glutamine and hydroxylamine. Hydrazine, a strictly competitive inhibitor of hydroxylamine in this process, also served as an acceptor of the $\gamma$-glutamyl group. No evidence could be obtained for the participation of adenine nucleotides or metal ions in the reaction $^{4-6}$ nor for transfer of the $\gamma$-glutamyl group to amino acids ${ }^{7-11}$. More rapid and extensive transfer was observed when donors were used that were more effective than glutamine as substrates for hydrolytic cleavage. Among such donors were the $\gamma$-L-glutamyl derivatives of cyclohexylamine, $p$-hydroxyaniline, and phenylhydrazine (or $p$-hydroxymethylphenylhydrazine). This and several other lines of evidence (e.g. constancy of ratios of specific activities toward hydrolysis and transfer throughout the purification procedure, identity of rates of heat and $\mathrm{pH}$ inactivation, inhibition of hydrolysis by nitrogenous $\gamma$-glutamyl acceptors), have lent support to the conclusion that hydrolytic and glutamyl-transfer reactions are catalyzed by the same protein.

Evidence for several of the reactions catalyzed by the mushroom glutamyltransferase is given in diagrammatic form by the chromatographic patterns shown in Fig. I. When $\mathrm{NH}_{4}{ }^{+}$, at rather high levels, was the acceptor, glutamine was formed in the presence of a donor such as $\gamma$-glutamylcyclohexylamine (Expt. A) or agaritine. Both glutamine and $\gamma$-glutamyl-p-hydroxyaniline served as donors of the glutamyl group to phenylhydrazine ${ }^{\star \star}$ (Expts. B and C, respectively). Finally, in a situation essentially the reverse of that in Expt. C, agaritine functioned as a $\gamma$-glutamyl donor to $p$-hydroxyaniline (Expt. D).

* Both substances are present in $A$. bisporus (J. Casimir; B. Levenberg, unpublished observations).

** Phenylhydrazine was used in place of $p$-hydroxymethylphenylhydrazine because of the extreme instability and difficulty of preparation of the latter ${ }^{3}$. 


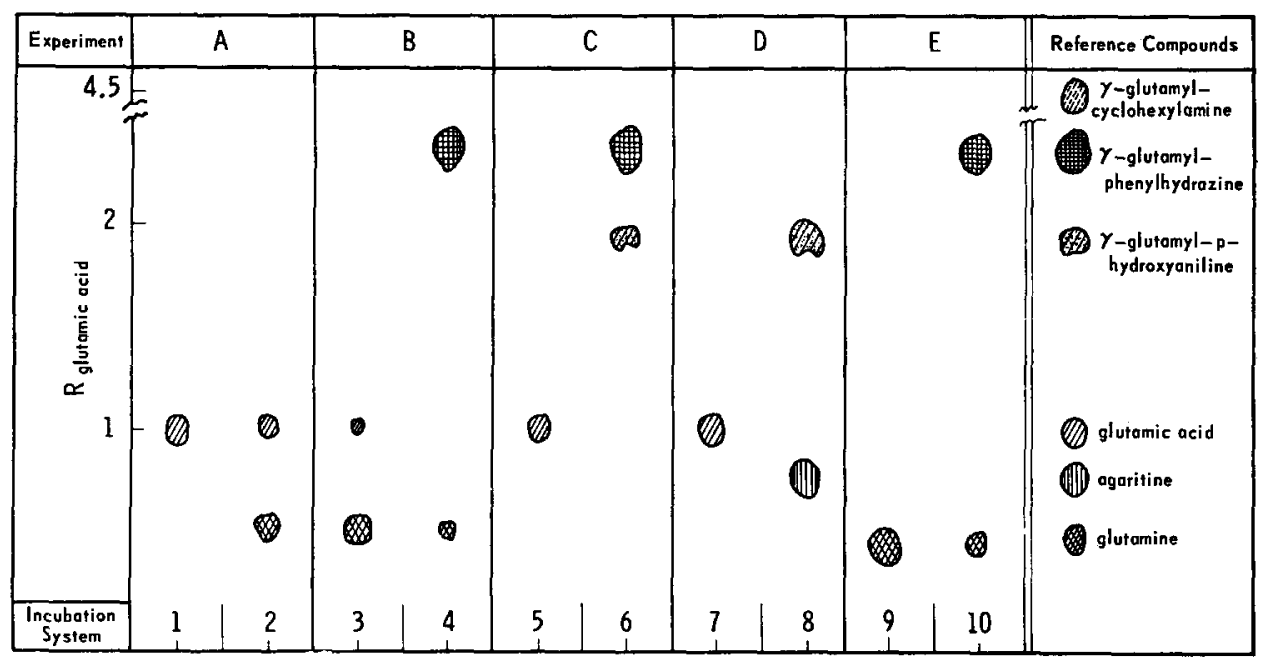

Fig. I. Diagrammatic representation of paper-chromatographic evidence for specific reactions catalyzed by mushroom $\gamma$-glutamyltransferase. Reaction components (in $\mu$ moles): Expt. A: I, $\gamma$-L-glutamylcyclohexylamine (2.5), Tris- $\mathrm{HCl}$ buffer $(\mathrm{pH} 9.0)(50) ; 2$, same as (I), plus $\mathrm{NH}_{4} \mathrm{Cl}$ (125). Expt. B: 3, L-glutamine (I6), potassium phosphate buffer (pH 7.0) (80); 4, same as (3), plus phenylhydrazine (I6). Expt. C: $5, \gamma$-L-glutamyl-p-hydroxyaniline $(7.5)$, Tris-maleate buffer ( $\mathrm{pH} 7.0)$ (I 50); 6, same as (5), plus phenylhydrazine (30). Expt. D: 7 , agaritine (7.5), Trismaleate buffer ( $\mathrm{pH} 7.0)\left(\mathrm{I}_{50}\right) ; 8$, same as $(7)$, plus $p$-hydroxyaniline (30). Expt. E: 9 and 10 , L-glutamine (Io), phenylhydrazine (Io), Tris $\mathrm{HCl}$ buffer $(\mathrm{pH} 7.4)$ (5o). Tubes I through 8 and Tube ro contajned purified $A$. bisporus $\gamma$-glutamyltransferase, $60 \mu$ g protein; Tubes 9 and 10 contained active glutamotransferase from $P$. vulgaris (dialyzed, centrifuged extract prepared according to WAELSCH ${ }^{12}$ ), $3.0 \mathrm{mg}$ protein. Final volume of each tube was $0.50 \mathrm{ml}$. All incubations were for $90 \mathrm{~min}$ at $30^{\circ}$. Reactions were terminated by placing samples in a boiling-water bath for several minutes. The tubes were cooled and centrifuged to remove protein debris; then aliquots of the supernatant solutions were chromatographed on Whatman No. 3 paper with a $n$-butanolacetic acid-water ( $8: 2: 5, \mathrm{v} / \mathrm{v}$ ) solvent, using a minimum of three cycles of multiple development ${ }^{13}$ The spots diagrammed represent ninhydrin-reactive areas of the chromatogram. In most cases, confirmation of the identity of a reaction product was made possible by application of the ferricyanide spray for reducing substances ${ }^{14}$ (positive for hydrazine and aminophenol derivatives). Determination of the ultraviolet spectrum and enzymatic activity of presumed arylhydrazides or anilides eluted from the paper provided further proof of identity. Phenylhydrazine, $p$-hydroxy methylphenylhydrazine, $p$-hydroxyaniline and their chemical degradation products migrated far ahead of the other substances shown, and hence are not indicated in the diagram. In each ex. periment, appropriate control samples (e.g. unincubated, incubated with boiled enzyme, incubated without donor substrate) were carried through the entire analysis. Such controls invariably afforded negative results.

Neither glutamine synthetase (EC 6.3.r.2) ${ }^{15}$ nor, as shown in this laboratory, kidney $\gamma$-glutamyltranspeptidase ${ }^{7,8}$ or glutathionase ${ }^{9}$ utilize phenylhydrazine as an acceptor. Mushroom $\gamma$-glutamyltransferase more closely resembles the activity of glutamotransferase from Proteus vulgaris ${ }^{5,12,16}$ in its ability to effect transfer of the $\gamma$-glutamyl group to hydroxylamine, hydrazine, and ammonia, and its non-utilization of amino acids as acceptors. However, as shown by the results of Expt. E, the bacterial enzyme did not catalyze glutamyl transfer to phenylhydrazine under conditions in which the mushroom enzyme was active in such a reaction. A further point of difference can be noted in the lack of hydrolytic activity of the glutamotransferase of $P$. vulgaris (Expt. E).

The mushroom enzyme has been detected only in members of the family Agarica- 
ceae that contain agaritine ${ }^{2}$. It has not been found in extracts of a variety of other mushrooms, bacteria, or higher plant and animal tissues. Thus it appears probable that the reversible enzymatic transfer of the glutamyl group between agaritine and $\gamma$-glutamyl- $p$-hydroxyaniline plays a role in the metabolism, and perhaps also in the final stages of biosynthesis, of these two unusual substances. It may be anticipated that other $\gamma$-glutamyltransferases similarly possessing unique donor and acceptor specificity will reveal their presence in other organisms from which compounds containing the $\gamma$-glutamyl function in linkage with nitrogenous residues of a non$\alpha$-amino acid character have recently been isolated ${ }^{17}$.

Details of these findings will be published elsewhere in the near future. This investigation was supported by Grants E-2966 and GM-I0359 from the National Institutes of Health, U.S. Public Health Service.

Department of Biological Chemistry,

The University of Michigan,

Helen J. Gigliotti ${ }^{\star}$ Ann Arbor, Mich. (U.S.A.)

1 J. Jadot, J. Casimir and M. Renard, Biochim. Biophys. Acta, 43 (ig6o) 322.

2 B. Levenberg, $J$. Am. Chem. Soc., 83 (I96I) 503.

3 R. B. Kelly, E. G. Daniels and J. W. Hinman, J. Org. Chem., 27 (1962) 3229.

4 P. K. Stumpf, W. D. Loomis and C. Michelson, Arch. Biochem. Biophys., 30 (1951) I 26.

s H. WAelsch, in F. F. Nord, Advan. Enzymol., I3 (I952) 237.

6 A. Lajtha, P. Mela and H. Waelsch, J. Biol. Chem., 205 (1953) 553.

7 C. S. Hanes, F. J. R. Hird and F. A. Isherwood, Natuve, I66 (I950) 288.

${ }^{8}$ F. J. R. Hird and P. H. Springell, Biochem. J., 56 (I954) 4 I 7 .

9 F. BrNkLEY, J. Biol. Chem., 236 (I96I) I075.

10 W. J, Williams and C. B. Thorne, J. Biol. Chem., 2 Io (1954) 203.

11 J. F. Thompson, D. H. Turner and R. K. Gering, Federation Proc., 2 I (I962) 5.

$12 \mathrm{H}$. WAELSCH, in S. P. Colowick and N. O. Kaplan, Methods in Enzymology, Vol. 2, Academic Press, New York, I955, p. 267.

13 A. Jeanes, C. S. Wise And R. J. Dimler, Anal. Chem., 23 (I95I) 4 I 5.

14 M. Goldenberg, M. Faber, E. J. Alston and E. C. Chargaff, Science, iog (1949) 534.

15 W. H. Elliott, Biochem. J., 49 (I95I) ro6.

16 H. Waelsch, in W. D. McElroy and B. Glass, Phosphorus Metabolism, Vol. 2, Johns Hopkins Press, Baltimore, I952, p. Io9.

17 J. F. Thompson, C. J. Morris, W. N. Arnold and D. H. Turner, in J. T. Holden, Amino Acid Pools, Distribution, Formation and Function of Free Amino Acids, Elsevier, Amsterdam, I962, p. 54 .

Received December I6th, I963

* Present address: Scripps Clinic and Research Foundation, La Jolla, Calif. (U.S.A.)

** Research Career Development Awardee (GM-3I I5-K-3), U.S. Public Health Service.

Biochim. Biophys. Acta, 81 (1964) 618-620

\section{The phosphorylation of Tris by alkaline phosphatase}

PN 10093

Solutions of Tris and its conjugate acid $\left(\mathrm{p} K_{\mathrm{a}}=8.0\right)$ are frequently used as buffers in the study of enzyme-catalyzed reactions. In studies with alkaline phosphatase (orthophosphoric monoester phosphohydrolase, EC 3.I.3.I) (Escherichia coli), it has been found that the enzyme activity increases with the concentration of Tris buffer much 